\title{
Tunable H-Shaped Microstrip Antenna with Dual Feeding
}

\author{
Ayman S. Al-Zayed, Mohammed A. Kourah, and Samir F. Mahmoud \\ Department of Electrical Engineering, Kuwait University, P.O. Box 5969, 13060 Safat, Kuwait \\ Correspondence should be addressed to Ayman S. Al-Zayed; ayman.alzayed@ku.edu.kw
}

Received 13 April 2017; Revised 31 May 2017; Accepted 6 June 2017; Published 6 July 2017

Academic Editor: Jaume Anguera

Copyright (C) 2017 Ayman S. Al-Zayed et al. This is an open access article distributed under the Creative Commons Attribution License, which permits unrestricted use, distribution, and reproduction in any medium, provided the original work is properly cited.

\begin{abstract}
The design of a frequency reconfigurable dual-band H-shaped microstrip antenna fed by two coaxial probes is presented. Each probe excites one of the two fundamental modes of the antenna which are linearly polarized and orthogonal to each other. The antenna is symmetrically loaded with four varactor diodes to simultaneously tune these two modes. Simulation results show that the tunable range of the first mode is between 1.69 and $2.19 \mathrm{GHz}(1.3: 1$ tuning ratio), whereas it is between $1.94 \mathrm{and} 2.72 \mathrm{GHz}(1.4: 1$ tuning ratio) for the second mode. In the range between 1.94 and $2.19 \mathrm{GHz}$, the radiation of the proposed antenna can be switched between two orthogonal linear polarizations by a simple adjustment to the capacitance of the varactor diodes. The proposed antenna achieves a good performance in terms of port-to-port isolation, directivity, and cross-polarization.
\end{abstract}

\section{Introduction}

The first attempt to analyze the radiation behavior of the $\mathrm{H}$-shaped microstrip antenna (HMSA) was carried out using the generalized cavity model to obtain the radiation characteristics of the first resonance [1]. These include the resonant frequency, radiation pattern, and input impedance. The study confirmed that when compared to the conventional rectangular patch, the HMSA exhibits compactness and narrower bandwidth as well as broader beam-width. In [2], a short-circuited HMSA was shown to be a suitable candidate for monolithic microwave integrated circuits applications (MMIC) and was characterized using the finite differencetime domain method (FDTD). Also, a circularly polarized HMSA has been presented in [3] where the $\mathrm{H}$-shape was formed from a square patch.

Multiple resonant modes of the HMSA can be simultaneously excited making it a multiband antenna. In [4], the first four resonant modes of the HMSA were analyzed, and design equations for their resonant frequencies were developed. The analysis was based on the concept of placing electric and magnetic walls at the planes of symmetry and predicting the current distribution over the patch. It was also shown that the HMSA suppresses harmonic radiation thus reducing unwanted electromagnetic interference between transmitter systems. In [5], the formulae of the resonant frequencies were modified, and a design methodology for the HMSA based on the modified formulae was presented. The HMSA has also been analyzed using different approaches such as an equivalent tank circuit model [6] and transmission line model [7]. Recently, single- and dual-band frequency reconfigurable designs of a probe-fed HMSA have been developed [8]. These designs were varactor-loaded with the aim of tuning higher order modes of the HMSA.

In this paper, a dual-band dual-polarized frequency reconfigurable HMSA is presented. Varactor diodes are used to achieve the frequency-reconfigurability aspect of the design, whereas the antenna is fed using two coaxial probes to achieve the dual-band operation. The main features of the proposed antenna are compactness, harmonic suppression, and the stability of the radiation parameters over the tunable range. The proposed antenna presents a simple low-cost candidate for several contemporary applications such as LongTerm Evolution (LTE) carrier aggregation and polarizationdiverse schemes. The two bands of the proposed antenna are operated at the first two resonant modes of the HMSA whose analysis is reviewed next. 


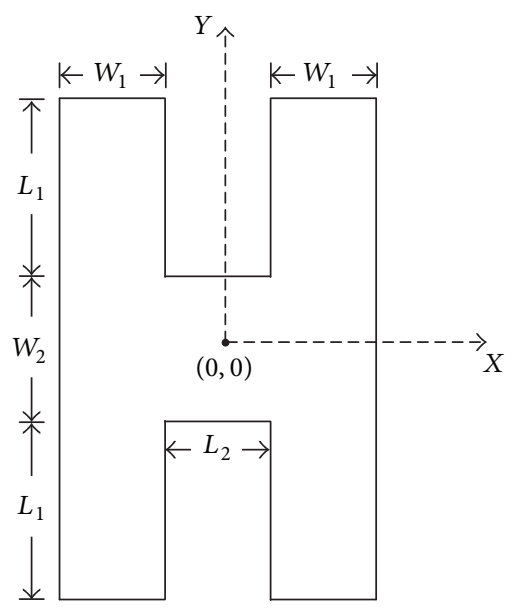

Figure 1: Geometry of the H-shaped microstrip antenna.

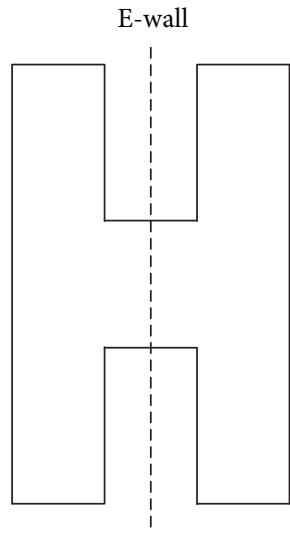

(a)

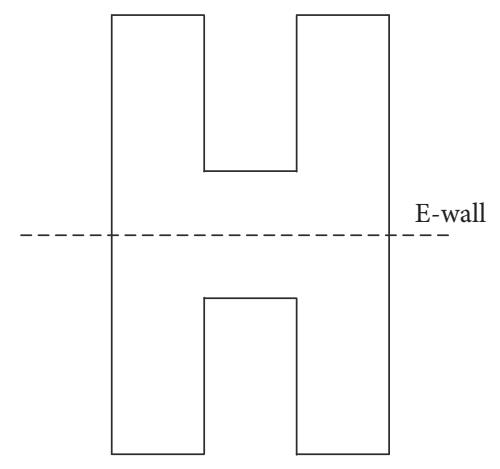

(b)
Figure 2: The electric walls for the first two HMSA modes: (a) the $\mathrm{TM}_{10}$ mode and (b) the $\mathrm{TM}_{01}$ mode.

\section{Analysis of the First Two Resonant Modes of the HMSA}

The first two resonant modes of the HMSA, whose geometry is shown in Figure 1, can be denoted by $\mathrm{TM}_{10}$ and $\mathrm{TM}_{01}$ following the cavity model notation. These two modes are similar to the first two modes of the conventional rectangular patch antenna. When operating at any of these two modes, the electrical length of the HMSA is considered to be half a wavelength. However, the spatial variation of the normal electric field for the first mode $\left(\mathrm{TM}_{10}\right)$ is along the $x$ direction, whereas it is along the $y$ direction for the second mode $\left(\mathrm{TM}_{01}\right)$. For either mode, the field amplitude has a high value along the edges and a null along one of symmetry axes of the antenna. Figure 2 shows the electric field null for each mode. This null is also called an electric wall (E-wall).

When the antenna is fed along an E-wall of a certain mode, this mode is suppressed. Therefore, feeding along the $y$-axis suppresses the first mode, whereas feeding along the $x$-axis suppresses the second mode. In other words, feeding along either of the symmetry axes suppresses one of the two

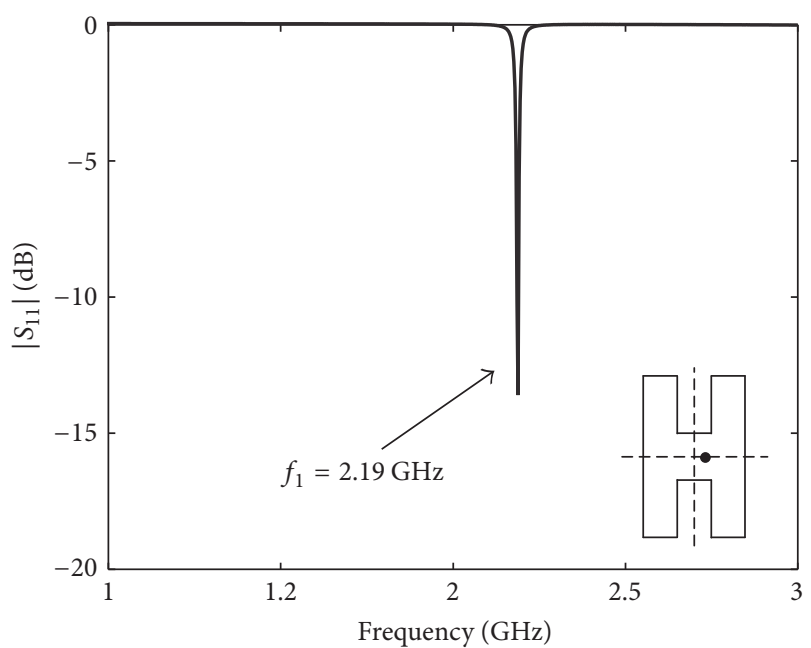

FIgURE 3: Simulated $\left|S_{11}\right|$ for the HMSA supporting only the first mode with feed located at $(1.5,0) \mathrm{mm}$.

modes while the other is excited. It is interesting to point out that feeding at the center should be avoided because it suppresses both modes.

Before discussing the varactor-loaded HMSA design, single- and dual-probe-fed unloaded designs are presented. First, two single-probe-fed designs are discussed. In the first design, only the first resonant mode is excited by feeding along the $x$-axis, whereas only the second resonant mode is excited in the second design by feeding along the $y$-axis. Afterwards, the two single-band designs are merged in a dualband dual-probe-fed design which excites both the $\mathrm{TM}_{10}$ and the $\mathrm{TM}_{01}$ modes. The three designs are simulated using a commercial full-wave simulator to investigate their return losses and radiation patterns.

2.1. Unloaded Design Supporting the First Mode. For properly exciting only the first mode $\left(\mathrm{TM}_{10}\right)$, the feed is located at the point $(1.5,0) \mathrm{mm}$ according to the coordinates system proposed in Figure 1. The simulated return loss is shown in Figure 3. The resonant frequency of the first mode, denoted by $f_{1}$, is observed at $2.19 \mathrm{GHz}$ with a return loss of $13.5 \mathrm{~dB}$.

In Figure 4, the normalized radiation patterns at the principal planes when operating at $f_{1}$ are presented. The radiation is linearly polarized and broadside with maximum directivity of $6.77 \mathrm{dBi}$ and cross-polarization levels below $-30 \mathrm{~dB}$.

2.2. Unloaded Design Supporting the Second Mode. Feeding at the point $(0,-5) \mathrm{mm}$ provides a proper excitation for the second mode $\left(\mathrm{TM}_{01}\right)$, while the first mode is suppressed. Simulation results show that the resonant frequency of the second mode, denoted by $f_{2}$, is $2.72 \mathrm{GHz}$ with $20 \mathrm{~dB}$ return loss as shown in Figure 5. In Figure 6, the normalized radiation patterns of the second mode are shown. The maximum directivity for this mode is $7.1 \mathrm{dBi}$ and cross-polarization levels below $-20 \mathrm{~dB}$. The polarization of the radiated field is linear and orthogonal to that produced by the first mode. This 


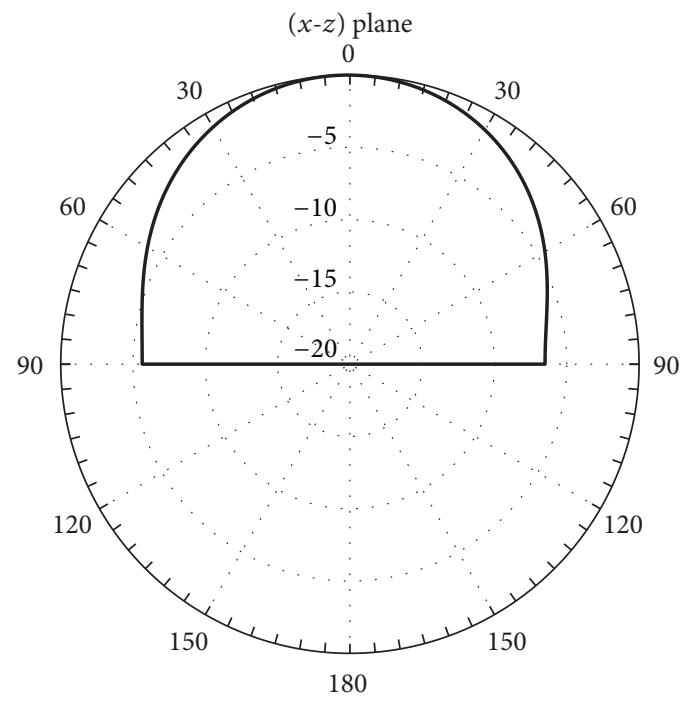

(a)

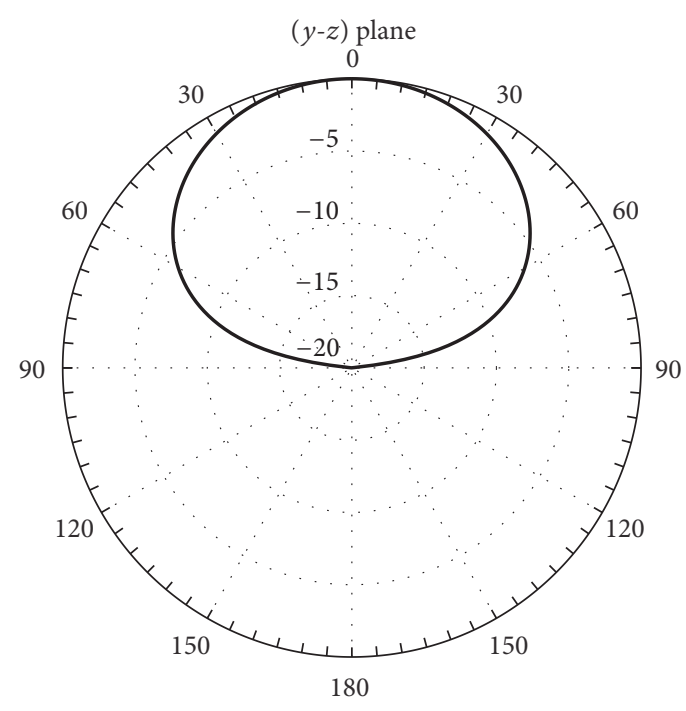

(b)

FIGURE 4: Normalized radiation patterns for the probe-fed HMSA supporting the first mode at $2.19 \mathrm{GHz}$ : (a) copolar component $E_{\theta}$ at the $\mathrm{H}$-plane ( $x-z$ plane) and (b) copolar component $E_{\Phi}$ at the E-plane $(y-z$ plane).

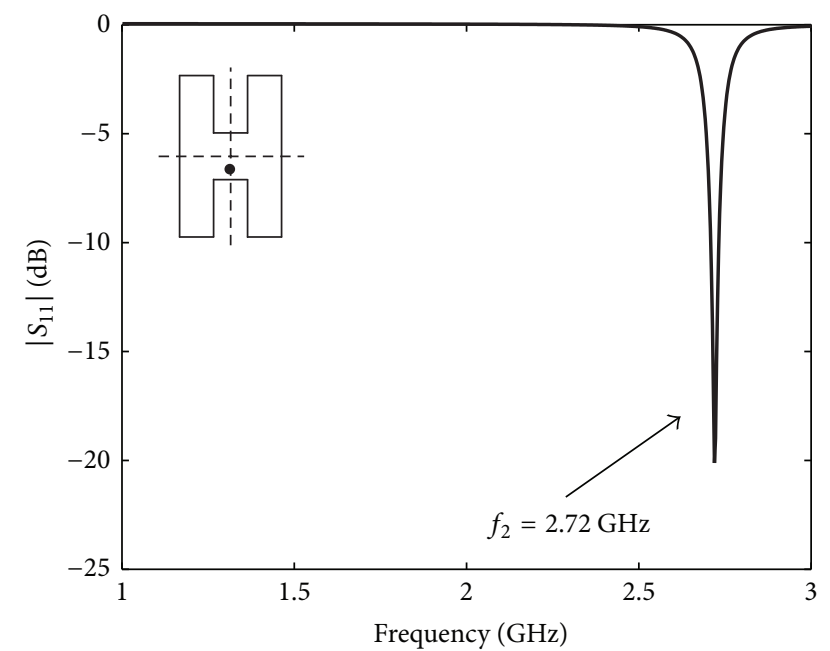

Figure 5: Simulated $\left|S_{11}\right|$ for the HMSA supporting only the second mode with feed located at $(0,-5) \mathrm{mm}$.

can be confirmed by comparing the copolar components of Figures 4 and 6 .

\section{Unloaded Dual-Probe-Fed Design Supporting Both the First and Second Modes}

The first two modes are linearly polarized and orthogonal in polarization, a fact that can be used to achieve dual-band dual-polarization operation. In other words, the antenna operates at two bands each with a different polarization. To realize such operation, two feeds are used instead of one; each is located at a point that excites a single mode. These locations are the same as discussed in the previous two designs. The first feed $(P 1)$ excites the first mode and is located at $(1.5,0)$ $\mathrm{mm}$, whereas the second feed $(P 2)$ excites the second mode and is located at $(0,-5) \mathrm{mm}$. It can be observed from the $\left|S_{11}\right|$ and $\left|S_{22}\right|$ plots shown in Figures 7 (a) and 7(b), respectively, that the frequencies of the first two modes remain the same as that of the single-fed designs. Also, the isolation between the feeds $\left(\left|S_{21}\right|\right)$ shown in Figure $7(\mathrm{c})$ is observed to be lower than $-20 \mathrm{~dB}$ at each of the two bands of operation. The radiation patterns for this design are identical to that in Figure 4 when operating at the first mode and to that in Figure 6 when operating at the second mode.

\section{Varactor-Loaded Dual-Probe-Fed Design}

In this section, the previously discussed dual-probe-fed design is extended with the capability to tune both bands simultaneously by loading the antenna with four varactor diodes as shown in Figure 8.

The varactors diodes are placed in specific locations (indicated in Figure 8) which have high normal electric field amplitudes of both the first and second modes. Therefore, the resonant frequencies of the two modes are simultaneously tuned, and any change in capacitance will change both frequencies. To bias the varactors, a bias tee connected to either port is used.

In single-probe single-band designs, the tunable range is usually that with $\left|S_{11}\right|<-10 \mathrm{~dB}$. This can be extended to dualprobe-fed dual-band antennas by limiting the tunable range of the first band to that with $\left|S_{11}\right|<-10 \mathrm{~dB}$ and the tunable range of the second band to that with $\left|S_{22}\right|<-10 \mathrm{~dB}$. Also, good isolation $\left(\left|S_{21}\right|<-10 \mathrm{~dB}\right)$ needs to be simultaneously achieved at the two bands. In this design, however, the fact that the two resonant frequencies depend on the value of $C$ and are simultaneously tuned must be considered. When 


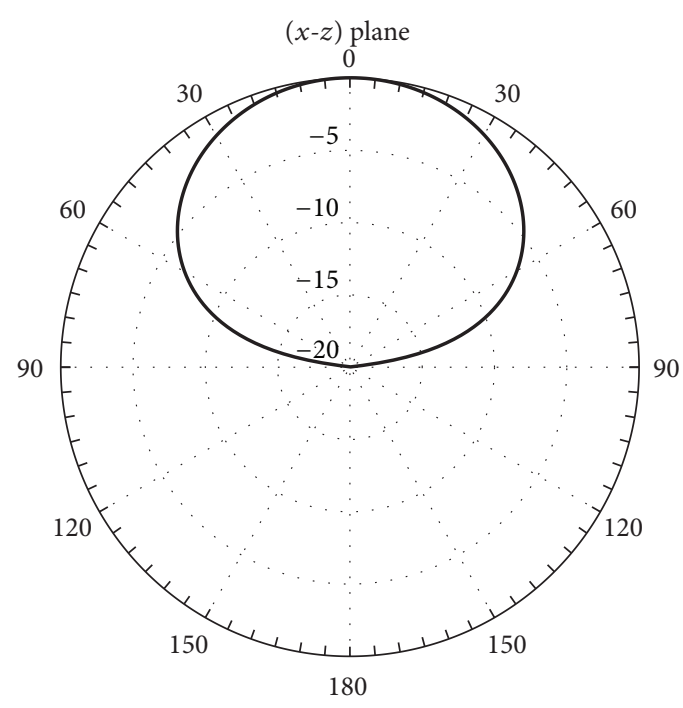

(a)

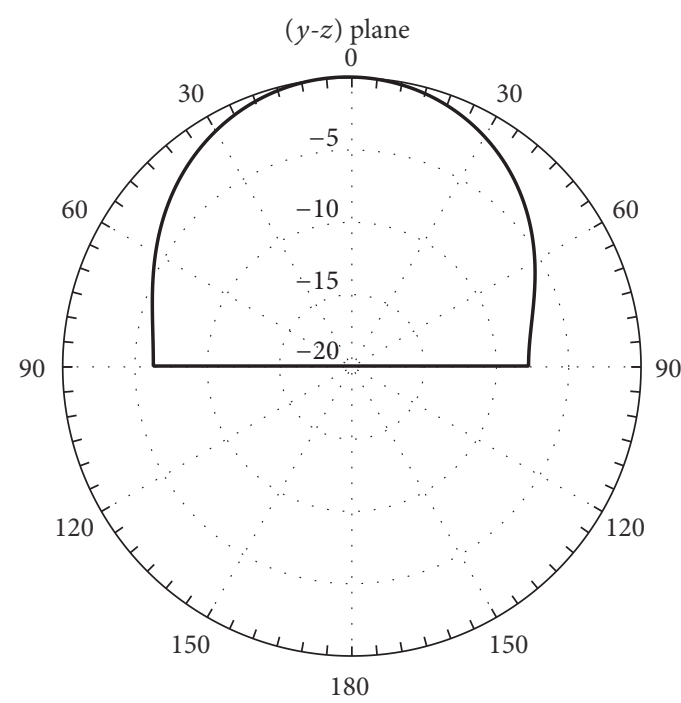

(b)

FIGURE 6: Normalized radiation patterns for the probe-fed HMSA supporting the second mode at 2.72 GHz: (a) copolar component $E_{\Phi}$ at the E-plane ( $x-z$ plane) and (b) copolar component $E_{\theta}$ at the H-plane ( $y$ - $z$ plane).

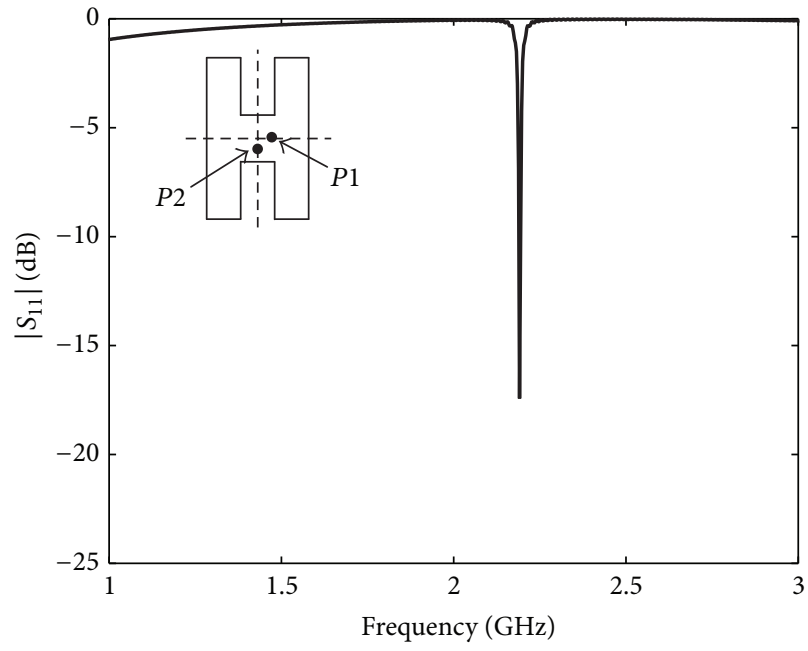

(a)

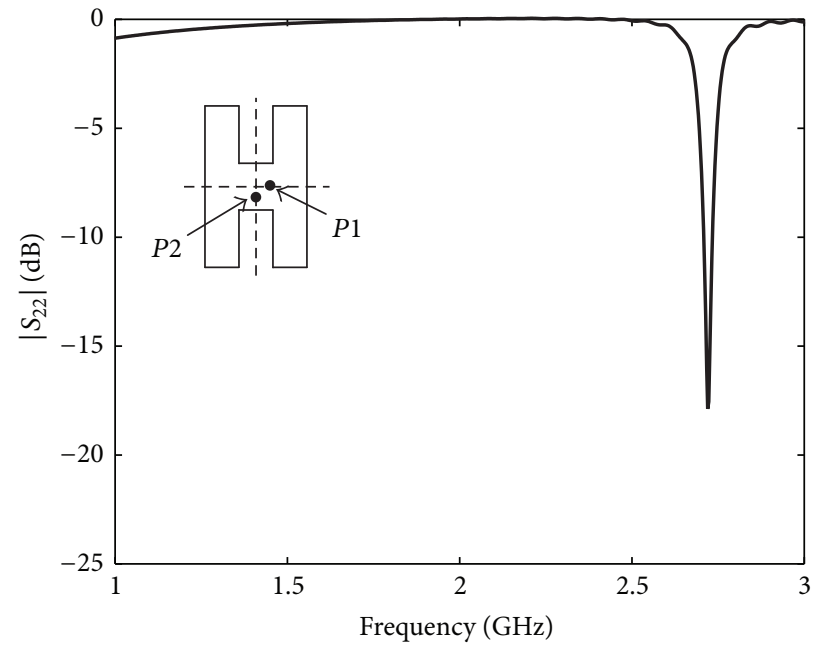

(b)

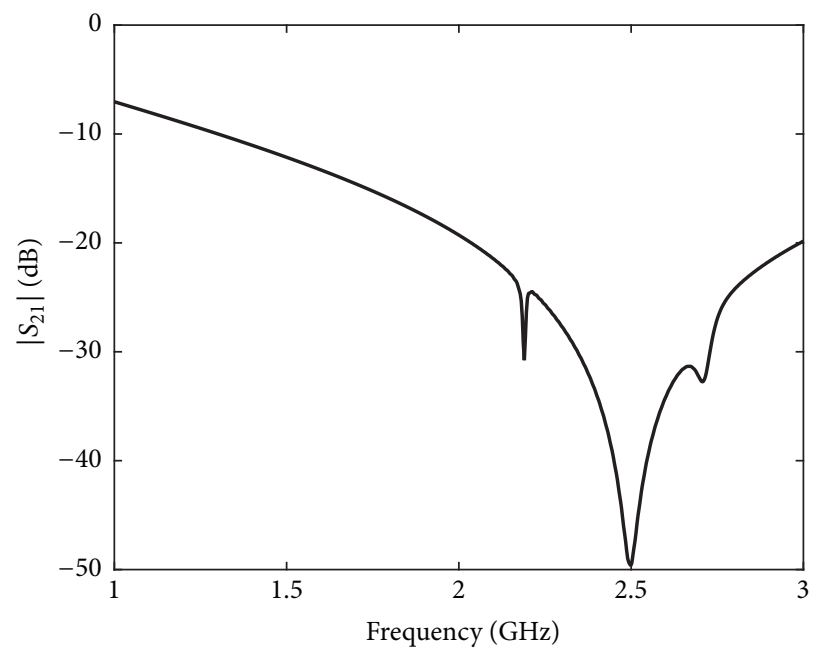

(c)

Figure 7: Simulated $S$-parameters for the dual-probe-fed HMSA: (a) $\left|S_{11}\right|$, (b) $\left|S_{22}\right|$, and (c) $\left|S_{21}\right|$. 


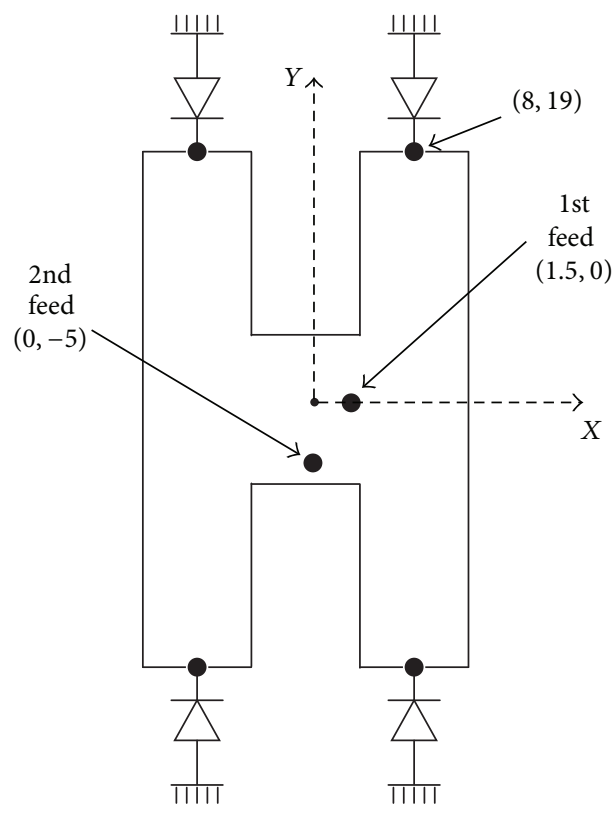

Figure 8: Top-view of the varactor-loaded dual-probe-fed HMSA supporting both the first and second modes (feed locations in $\mathrm{mm}$ ).

the capacitance is adjusted between $C_{\min }$ and $C_{\max }$, the first mode is tuned between $f_{1, \min }-f_{1, \max }$ and the second mode is tuned between $f_{2, \min }-f_{2, \max }$. Accordingly, a proper matching criterion is that the operation range should be limited to the capacitances range of values that simultaneously result in $\left|S_{11}\right|<-10 \mathrm{~dB}$ in the range $f_{1, \min }-f_{1, \text { max }}$ and $\left|S_{22}\right|<-10 \mathrm{~dB}$ in the range $f_{2, \min }-f_{2, \max }$. Moreover, at any value of $C$, the value of $\left|S_{21}\right|$ should be less than $-10 \mathrm{~dB}$ at both resonant frequencies.

The varactor-loaded dual-band design is simulated where each varactor diode is simply modeled as a variable capacitance $C$. The tuning of the resonant frequencies as the capacitance changes is shown in the $\left|S_{11}\right|$ and $\left|S_{22}\right|$ plots in Figures 9 and 10, respectively. It can be noted that the capacitance range between 0 and $1 \mathrm{pF}$ satisfied the matching criterion adopted earlier.

The first resonant frequency is tunable between $1.69 \mathrm{GHz}$ (when $C=1 \mathrm{pF}$ ) and $2.19 \mathrm{GHz}$ (when unloaded). This results in a tuning range of $25.9 \%$ and a tuning ratio of $1.3: 1$ for the first mode. On the other hand, the second resonant frequency is tunable between $1.94 \mathrm{GHz}$ (when $C=1 \mathrm{pF}$ ) and $2.72 \mathrm{GHz}$ (when unloaded). This means that for the second mode a tuning range of $33.4 \%$ and a tuning ratio of $1.4: 1$ are achieved. Isolation between the two feeds is an important factor to consider. It can be seen from the $\left|S_{21}\right|$ response in Figure 11 that the isolation $\left(\left|S_{21}\right|\right.$ level $)$ is below $-20 \mathrm{~dB}$ at both bands for every capacitance value in the range between 0 and $1 \mathrm{pF}$.

From the preceding results, the operational frequency range of the varactor-loaded design can be divided into three subranges according to the operational mode. The first subrange is between 1.69 and $1.94 \mathrm{GHz}$, where the first mode is the only operational mode. The second subrange is between 1.94 and $2.19 \mathrm{GHz}$, and at any frequency in this subrange, the operational mode can be either the first or the second

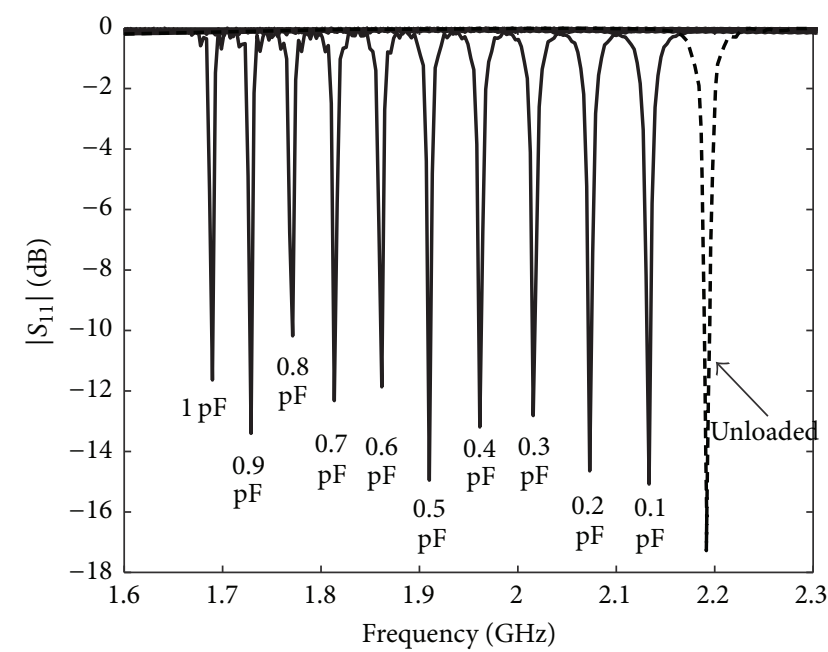

FIgURE 9: Simulated $\left|S_{11}\right|$ plots showing the tuned first mode of the varactor-tuned dual-probe-fed HMSA when the capacitance is varied between 0 and $1 \mathrm{pF}$ in $0.1 \mathrm{pF}$ increments.

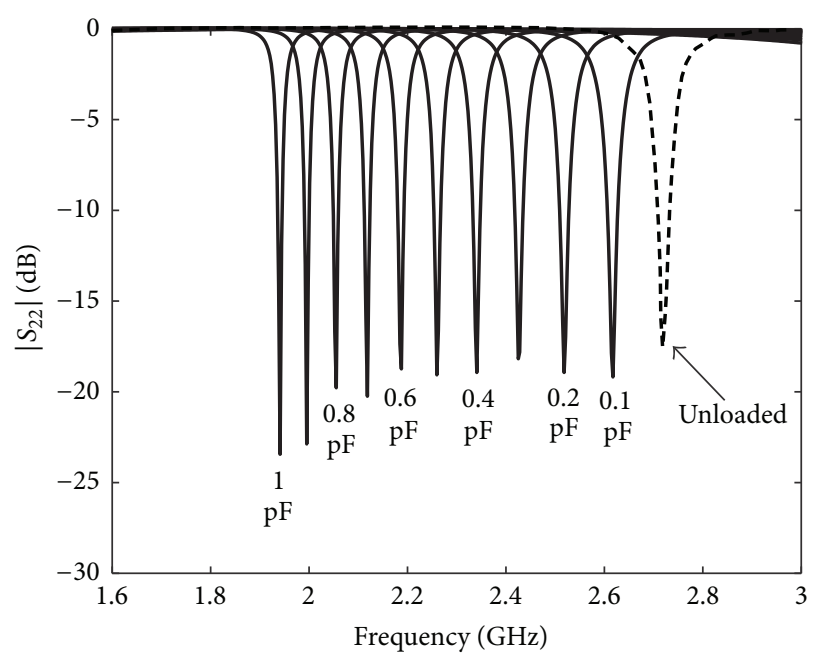

FIGURE 10: Simulated $\left|S_{22}\right|$ plots showing the tuned second mode of the varactor-tuned dual-probe-fed HMSA when the capacitance is varied between 0 and $1 \mathrm{pF}$ in $0.1 \mathrm{pF}$ increments.

mode depending on the value of the capacitance $C$. This is an interesting feature as it means that the operational polarization in this subrange can be switched between the two orthogonal linear polarizations attributed to the two modes by simply adjusting the capacitance value. To further illustrate, consider the operational frequency of $2 \mathrm{GHz}$. When $C=0.34 \mathrm{pF}$, the HMSA will radiate due to the first mode only as can be seen from Figures 9 and 10. However, when the capacitance is adjusted to $0.9 \mathrm{pF}$, the HMSA operates at $2 \mathrm{GHz}$ also, but this time the radiation is due to the second mode and is with orthogonal polarization to that when $C=0.34 \mathrm{pF}$. Finally, the third subrange is between 2.19 and $2.72 \mathrm{GHz}$, and the only operational mode is the second.

Next, the radiation performance of this design is discussed. The shape of the radiation patterns of this design 


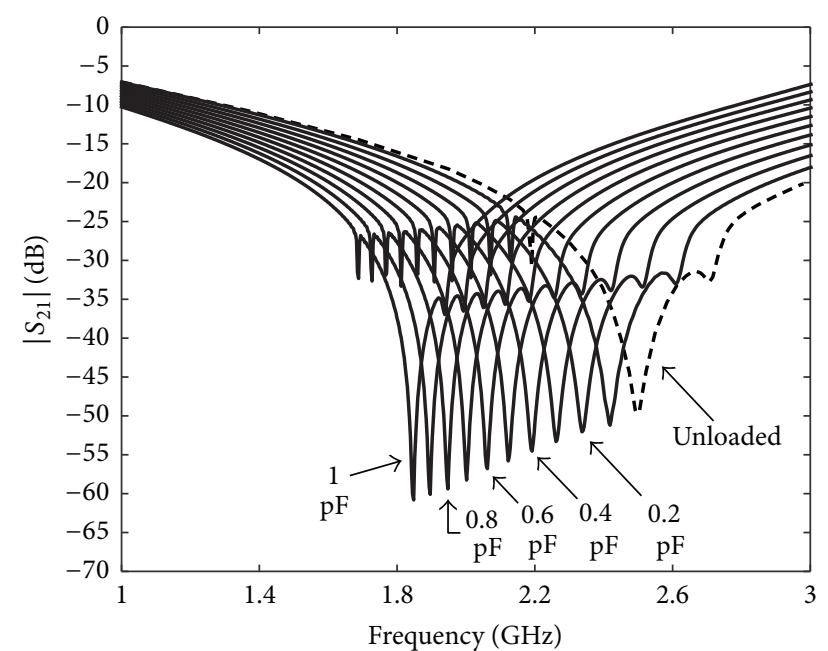

FIgURE 11: Simulated $\left|S_{21}\right|$ plots showing the isolation between the feeds of the varactor-tuned dual-probe-fed HMSA when the capacitance is varied between 0 and $1 \mathrm{pF}$ in $0.1 \mathrm{pF}$ increments.

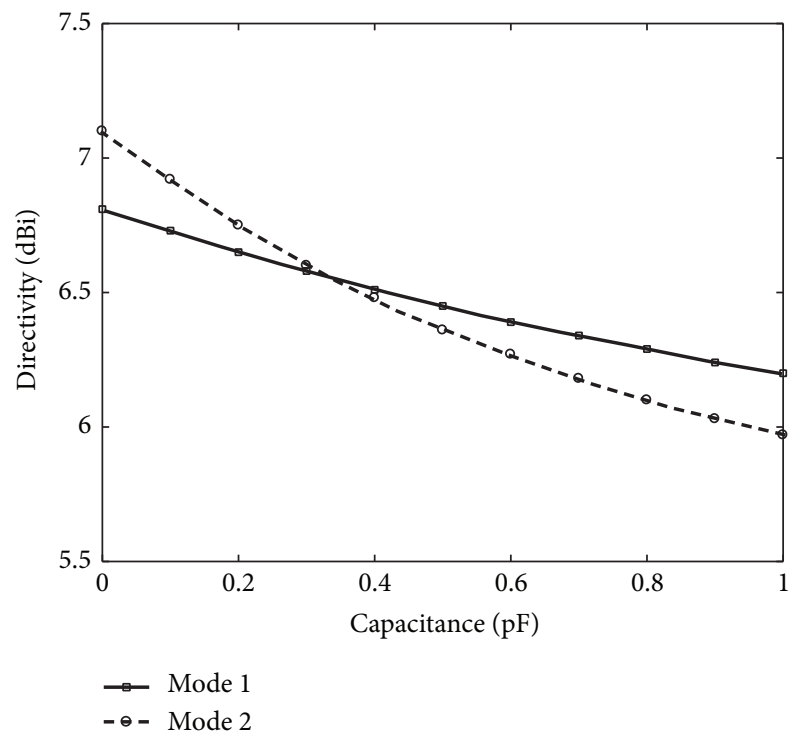

FIgURE 12: Directivity versus capacitance for both the first and second modes for the varactor-tuned dual-probe-fed HMSA.

are similar to that in Figure 4 when operating at the first mode and to that in Figure 6 when operating in the second mode. However, increasing the capacitance broadens the patterns of both modes resulting in lower directivity. The plots of directivity for both modes as a function of capacitance variation of the varactor diodes are shown in Figure 12. For the first mode, the directivity decreases from $6.81 \mathrm{dBi}$ at $2.19 \mathrm{GHz}$ to $6.2 \mathrm{dBi}$ at $1.69 \mathrm{GHz}$. On the other hand, it decreases from $7.1 \mathrm{dBi}$ at $2.72 \mathrm{GHz}$ to $6.0 \mathrm{dBi}$ at $1.94 \mathrm{GHz}$ for the second mode. As for the cross-polarization, its level is found to be below $-25 \mathrm{~dB}$ in the E-plane for both modes, whereas it is below $-30 \mathrm{~dB}$ in the $\mathrm{H}$-plane.

\section{Conclusion}

A frequency reconfigurable $\mathrm{H}$-shaped microstrip antenna has been proposed. The antenna is fed by two coaxial probes that excite two orthogonally polarized modes of the antenna. Frequency tuning of the two modes is made possible by loading the HMSA by four identical varactor diodes placed at positions of high electric field for both modes. Simulation results show that the tuning range of the first mode is $1.69-2.19 \mathrm{GHz}$ while it is $1.94-2.72 \mathrm{GHz}$ for the second mode. Within these ranges, the antenna's directivity remains above $6 \mathrm{dBi}$, and the cross-polarization levels are below $-25 \mathrm{~dB}$ for both modes. According to the operational mode, the operational frequency range has three subranges: the first operating only with the first mode; the second with both modes; and the third with only the second mode. At any frequency in the second subrange, the polarization can be switched between two orthogonal states by a simple adjustment to the capacitance of the varactor diodes.

\section{Conflicts of Interest}

The authors declare no conflicts of interest regarding the publication of this paper.

\section{References}

[1] V. Palanisamy and R. Garg, "Rectangular ring and h-shaped microstrip antennas-alternatives to rectangular patch antenna," Electronics Letters, vol. 21, no. 19, pp. 874-876, 1985.

[2] D. Singh, P. Gardner, and P. S. Hall, "Miniaturised microstrip antenna for MMIC applications," Electronics Letters, vol. 33, no. 22, pp. 1830-1831, 1997.

[3] W.-C. Liu and P.-C. Kao, "Design of a probe-fed H-shaped microstrip antenna for circular polarization," Journal of Electromagnetic Waves and Applications, vol. 21, no. 7, pp. 857-864, 2007.

[4] A. F. Sheta, A. Mohra, and S. F. Mahmoud, "Multi-band operation of a compact $\mathrm{H}$-shaped microstrip antenna," Microwave and Optical Technology Letters, vol. 35, no. 5, pp. 363-367, 2002.

[5] S. F. Ooi, S. K. Lee, A. Sambell, E. Korolkiewicz, and S. Scott, "Design of $\mathrm{H}$-shaped microstrip patch antennas," Microwave and Optical Technology Letters, vol. 49, no. 4, pp. 791-795, 2007.

[6] J. A. Ansari, S. K. Dubey, P. Singh, R. U. Khan, and B. R. Vishvakarma, "Analysis of compact H-shaped microstrip antenna," Microwave and Optical Technology Letters, vol. 50, no. 7, pp. 1779-1784, 2008.

[7] P. Kala, D. Ellstein, and K. H. Teo, "Investigation of an H-shaped microstrip patch antenna with inductive loading," International Journal of Microwave and Optical Technology, vol. 4, no. 2, pp. 99-106, 2009.

[8] A. S. Al-Zayed, M. A. Kourah, and S. F. Mahmoud, "Frequencyreconfigurable single- and dual-band designs of a multi-mode microstrip antenna," IET Microwaves, Antennas and Propagation, vol. 8, no. 13, pp. 1105-1112, 2014. 


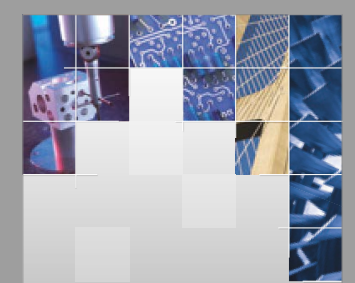

\section{Enfincering}
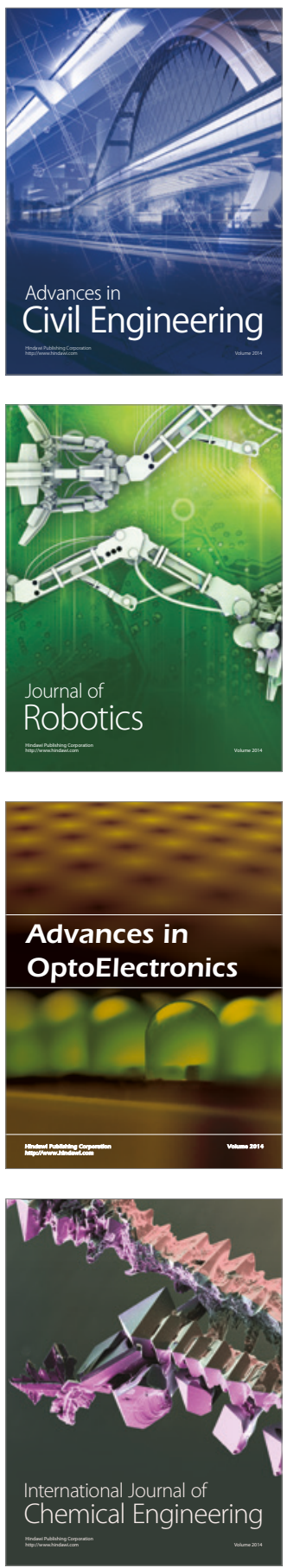

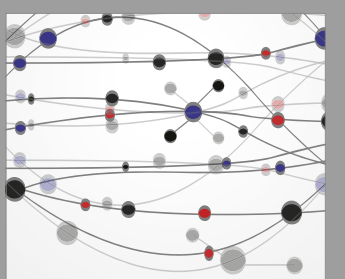

The Scientific World Journal

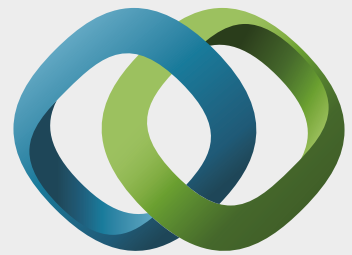

\section{Hindawi}

Submit your manuscripts at

https://www.hindawi.com
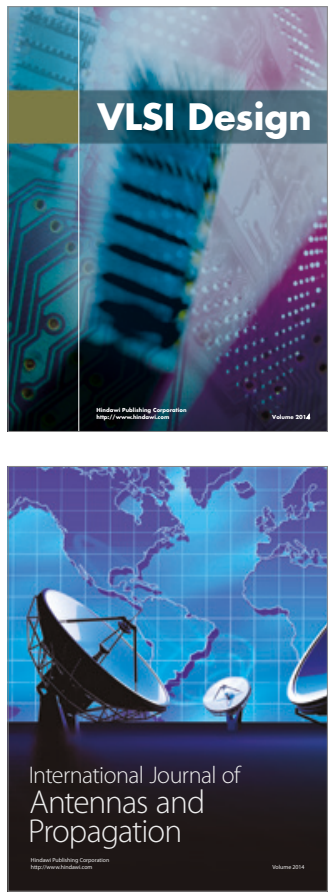

\section{Rotating}

Machinery
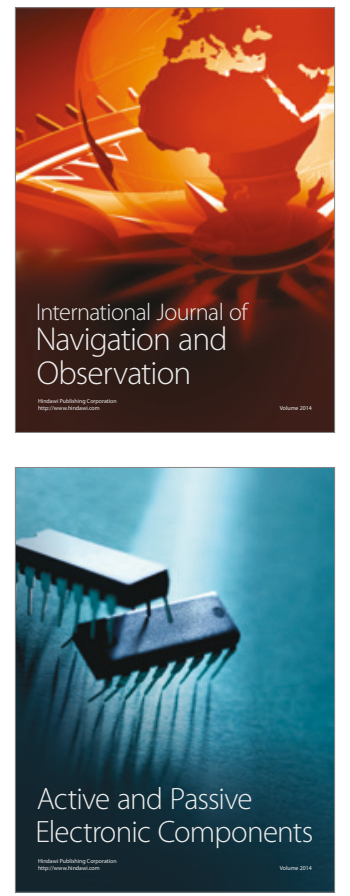
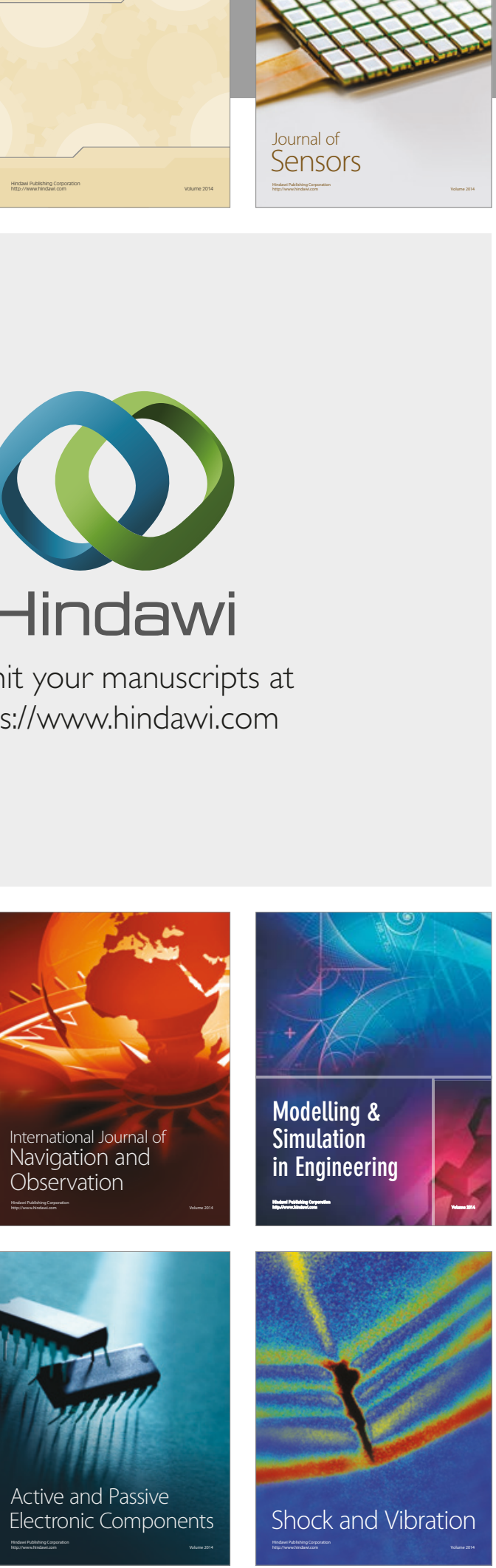
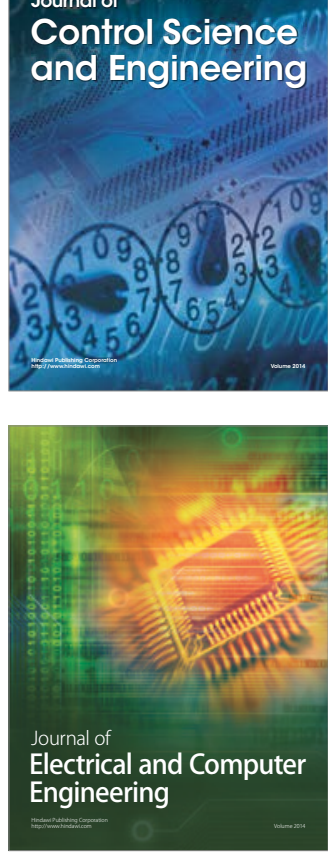

Distributed

Journal of

Control Science

and Engineering
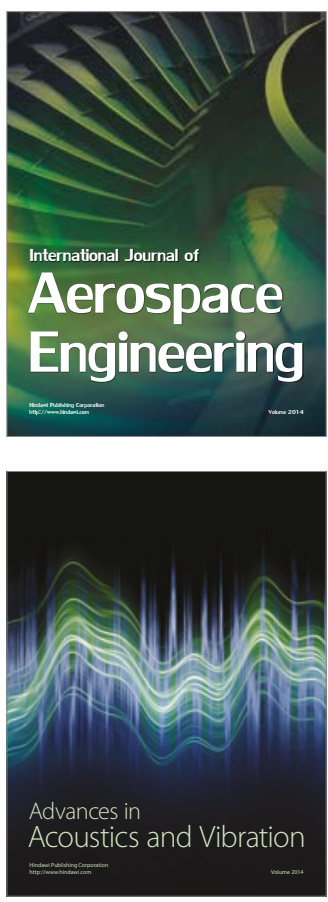

Sensor Networks 